\title{
PURE POLYURETHANE AND CASTOR OIL BASED POLYURETHANE: SYNTHESIS AND CHARACTERIZATION
}

\author{
M.A. Alaa ${ }^{1,2}$, Kamal Yusoh ${ }^{1}$ and S.F. Hasany ${ }^{1}$ \\ ${ }^{1}$ Faculty of Chemical \& Natural Resources Engineering, \\ Universiti Malaysia Pahang, Kuantan Malaysia \\ ${ }^{2}$ Department of Chemical Engineering, University of Technology, Baghdad, Iraq \\ Email: hjkamal@gmail.com; allavip63@yahoo.com
}

\begin{abstract}
In this study, the physico-chemical properties of high performance polyurethane synthesized from poly propylene glycol (PPG) in comparison with a combination of PPG and castor oil, is studied using the in-situ polymerization technique. The variations in properties of both types of polyurethanes are evaluated by Fourier transform infrared spectroscopy (FTIR), scanning electron microscopy (SEM), X-ray diffraction (XRD) and the thermogravimetric analysis (TGA) technique. Tensile strength properties were investigated by film tensile testing equipment. The results indicated the presence of large - $\mathrm{CH}$ stretching in the castor oil mixed polyurethane with a larger oxidative thermal stability over pure PPG polyurethanes. The tensile properties were found to be almost comparable in pure and mixed polymers, signifying the usage of mixed polymers in the future to overcome the environmental and economic crisis in polyurethane synthesis.
\end{abstract}

Keywords: Castor oil, in-situ polymerization, polyurethanes, vegetable oil, synthesis, poly propylene glycol.

\section{INTRODUCTION}

Polyurethanes (PUs) have been used extensively due to their excellent physical properties (e.g., low flexibility, high tensile strength, tear and abrasion resistance, solvent resistance, etc.) and high versatility in chemical structure [1, 2]. PU is generally synthesized from an isocyanate reaction with polyol. Polypropylene glycol (PPG) is a polyol basically derived from the petrochemical industry [3]. Due to the high rising costs of petrochemical feedstock and the enhanced public desire for environmentally friendly green products, research into the utilization of renewable resources to manufacture rigid PU is necessary at the present time $[4,5]$.

PU based on polyols is derived from different vegetable oils, like castor [6-8], sunflower and rapeseed oils [9]. Castor oil is one of the major natural vegetable oils that contain a hydroxyl group and so it is widely used in many chemical industries, especially in the production of PUs $[10,11]$. The synthesis of PU nanocomposites is prepared from natural oil, like castor oil, using HMDI and organically modified clay and covalently linked PU/n-HMDI composite, which is later collected successfully by the electro spinning process [6]. The study of the preparation from castor oil exhibited increasing diisocyanate groups in relation to the polyol amount and increased the strength at rupture of the obtained polymers and decreased polymer elongation, resulting in an increasing modulus [12]. A series of 1,4-butane diol chain extended PU nanocomposites based on castor oil, and 4,40-diphenylmethane diisocyanate (MDI) 
were synthesized with modified clay (Cloisite 30B) as the filler [13]. In this study pure PU and PUs based on castor oil were synthesized. Then, a comparative study of the behavioral changes in the physico-chemical properties of the PU made from a mixture of polyols consisting of PPG and dehydrated castor oil (15\%) via in-situ polymerization was conducted.

\section{Materials}

\section{EXPERIMENTAL SET-UP}

Commercial grade castor oil was purchased from the local market. It was dehydrated at $80{ }^{\circ} \mathrm{C}$ in a vacuum oven and characterized for hydroxyl value (148), acid value (2) and moisture content $(0.379 \%)$. PPG $(\mathrm{Mn}=4000)$ was supplied by SIGMA- Aldrich Company. The chain extender, 1, 4-butane diol, was procured from Himedia, India. The toluene diisocyanate (TDI), used as received, was supplied by SIGMA- Aldrich Company. The catalyst used in this research is DABCO-33LV, a mixture of triethylenediamine and di (propylene glycol) supplied by Air Products and Chemicals (United Kingdom).

\section{Synthesis Mechanism}

\section{Synthesis Mechanism of Pure PUs}

The synthesis mechanism of pure PUs using a pre-polymer technique as shown in Figure 1, comprises two main steps. First, PPG is reacted with diisocyanate, then vacuum de-gassed for 5 minutes with high speed stirring for 25 minutes at $75^{\circ} \mathrm{C}$ to achieve a homogeneous mixture and generate a pre-polymer with final isocyanate groups (in this case, polyunsaturated and amorphous). Second, the pre-polymer is reacted with a chain extender [14] in the presence of a DACO catalyst at high speed stirring for 1 minute at $75{ }^{\circ} \mathrm{C}$ to produce viscous $\mathrm{PU}$ (in this case, saturated and crystallized).

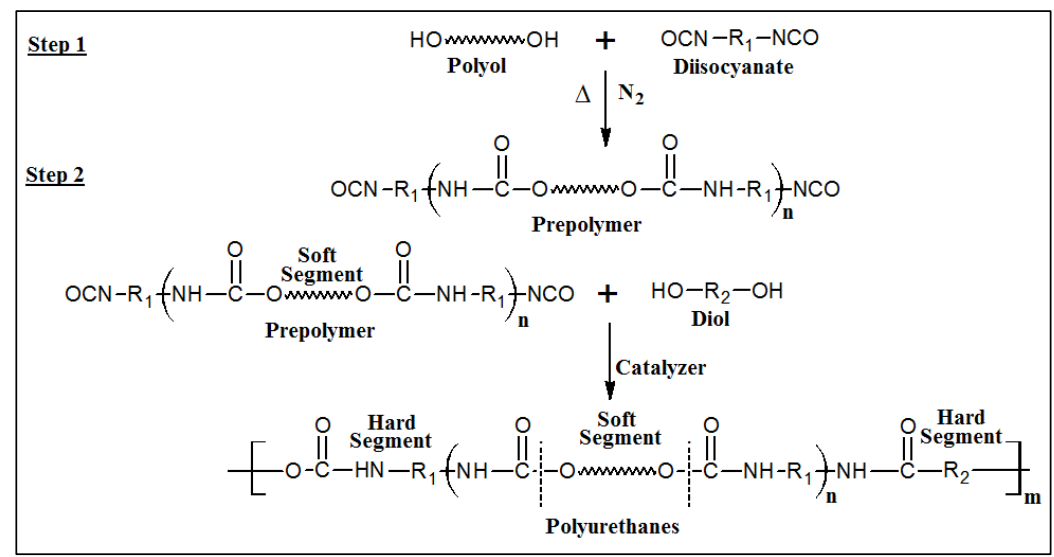

Figure 1. Schematic representation of the pure PU synthesis mechanism using the prepolymer technique.

\section{Synthesis Mechanism of Castor-oil-based PUs}

The synthesis mechanism of neat COPUs using the pre-polymer technique shown in Figure 2 comprises two main steps; first, the dehydrated castor oil $(15 \%)$ is mixed with the already dehydrated PPG, and second, a polyol mixture of PPG $+15 \%$ castor oil is 
reacted with diisocyanate, which was vacuum degassed for 5 minutes with high speed stirring for 25 minute at $75{ }^{\circ} \mathrm{C}$ prior to mixing to achieve a homogeneous mixture and generate a castor-oil-based pre-polymer with final isocyanate groups, followed by reaction with a chain extender [14] in the presence of a catalyst at high speed stirring for 1 minute at $75^{\circ} \mathrm{C}$ to produce viscous COPUs (in this case, saturated and crystallized).

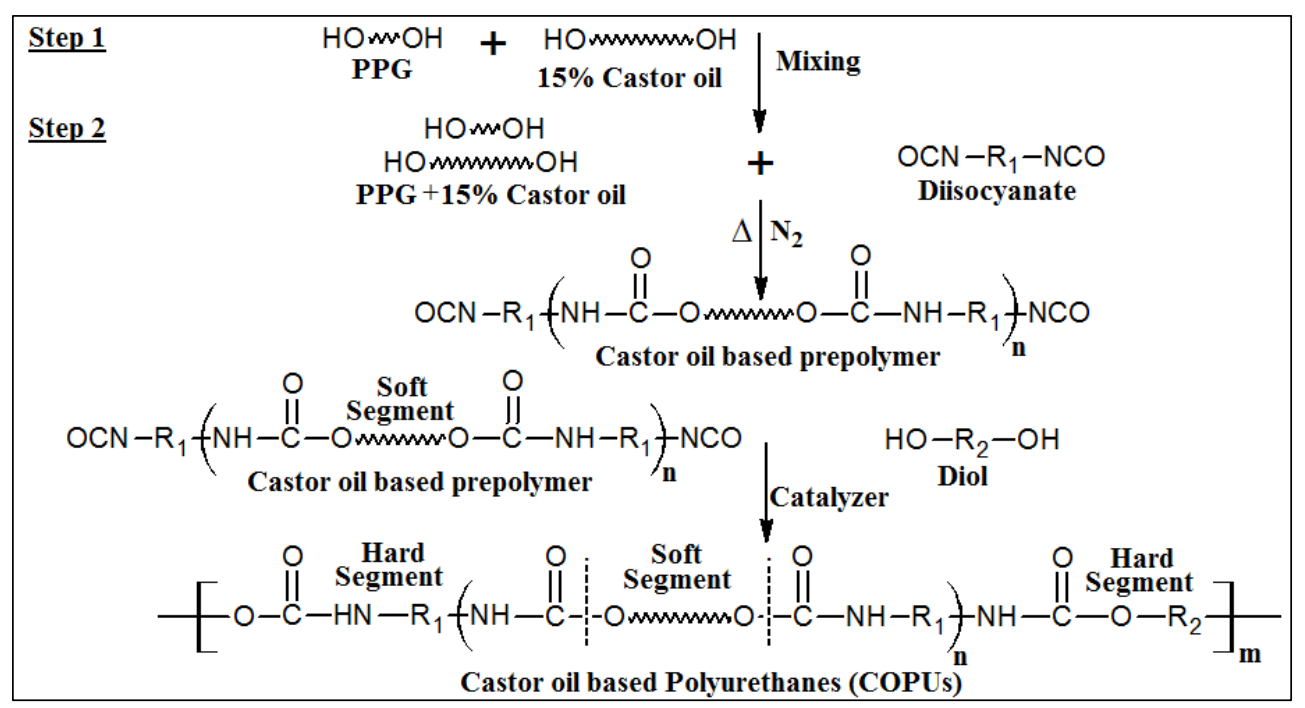

Figure 2: Schematic representation of the synthesis mechanism of neat COPUs using the pre-polymer technique.

\section{Characterization Technique}

Fourier transform infrared spectroscopy (FTIR) analysis of PUs was undertaken using a Vector-22 FT-IR spectrometer (Nicolet 5DX FT-IR) with a resolution of $1 \mathrm{~cm}^{-1}$ from 4000 to $400 \mathrm{~cm}^{-1}$. PU thermal stability (thermogravimetric analysis (TGA)) was tested using a Universal V4.5A, TA instrument under a nitrogen atmosphere. The crystal structure of the pure PUs and COPUs was analyzed by X-ray diffraction (XRD), using an X-ray diffractometer (Rigaku Mini Flex II, Japan) employing a graphite monochromator and $\mathrm{CuK} \alpha$ radiation $(1 \mathrm{~nm})$. Scanning electron microscopy (SEM) was carried out on a JEOL 6300F machine at an acceleration voltage of $5 \mathrm{KV}$. Tensile testing of the nanocomposite film was carried out on an instron model 4505 universal testing machine at $25^{\circ} \mathrm{C}$, with a load cell of $5 \mathrm{KN}$ and following ASTM D 638. The crosshead speed was set to $2 \mathrm{~mm} / \mathrm{min}$. Samples were cut in a dumbbell shape with an ASTM D 638 (type V).

\section{RESULTS AND DISCUSSION}

\section{FTIR Analysis}

The micro-domain structures of the pure PU and castor oil based PU were analyzed by FTIR as shown in Figure 3. A small broad band in the range $4000-3500 \mathrm{~cm}^{-1}$ was observed in both samples relating to the $\mathrm{O}-\mathrm{H}$ stretching vibrations from either water or hydroxyl terminated compounds, and $\mathrm{N}-\mathrm{H}$ stretching vibrations from either urea or the amine group $[15,16]$. The $\mathrm{CH}-\mathrm{CH}_{3}$ peak stretchings are more prominent in the castor oil based PU, then the pure PU which may be due to 


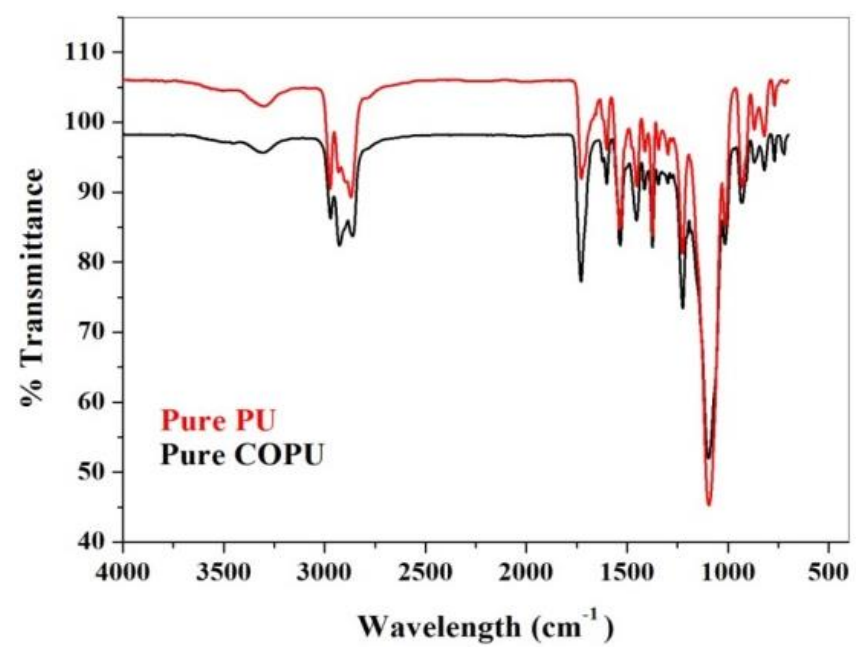

Figure 3. Comparative FTIR spectra for PU (pure PPG \& PPG and castor oil) the larger organic chains present in castor-oil-based PU. Peaks at $1727 \mathrm{~cm}^{-1}$ represent $(\mathrm{C}=\mathrm{O})$ non-bonded urethanes [13], which are likely to be present in larger numbers, in the castor-oil-based PU synthesis.

\section{TGA Analysis}

The result of the TGA (Figure 4) shows the thermal stability of pure PU and castor-oilbased PU under identical conditions and a comparison of the weight losses that occurred. The thermal stability of these polymers generally starts above $200{ }^{\circ} \mathrm{C}$ [17]. It can be seen from Figure 2 that the onset decomposition temperature starts from $250{ }^{\circ} \mathrm{C}$ and $235{ }^{\circ} \mathrm{C}$ for pure PU and castor-oil-based PU, respectively. At $400{ }^{\circ} \mathrm{C}$ almost $85 \%$ of the pure PU decomposed while the castor-oil-based PUs showed less than $80 \%$ decomposition, which may be due to the different polyol conditions when PPG is mixed with castor oil which, in turn, may be due to the presence of low hydroxyl content polyols in the formulation which improved the thermal resistance of the castor-oil-based PU samples. The overall thermal stability of the PUs showed a slight decreasing trend as the rigid segments content increased, which is similar to the findings in [17] in which it was concluded that PU based on vegetable oils has a better oxidative thermal stability than PU based on PPG [18].

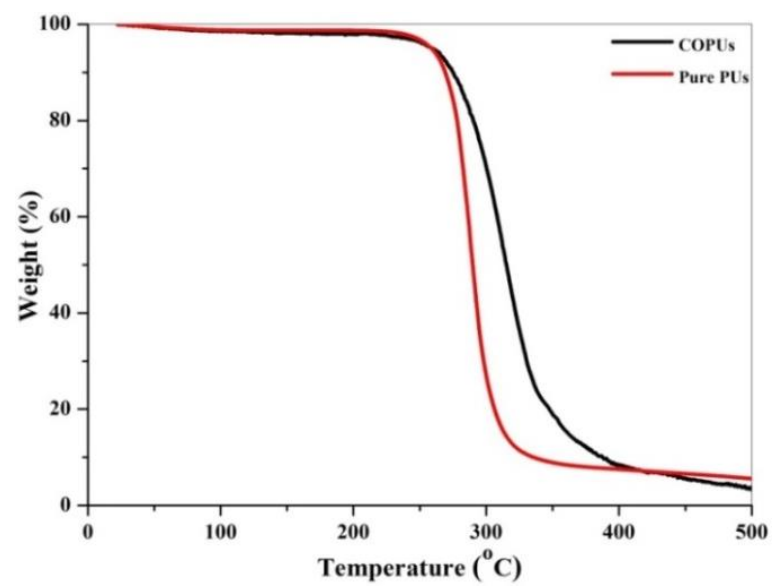

Figure 4. Comparative TGA graph for PU (pure PPG \& PPG and castor oil). 


\section{XRD of PU Studies}

The XRD patterns of pure PU and COPU are presented in Figure 5. The pure PU X-ray patterns display the presence of two peaks at $2 \theta=20.03\left(\mathrm{~d}\right.$ ang $\left.=4.430{ }^{\circ} \mathrm{A}\right)$ and $2 \theta=$ $28.77\left(\mathrm{~d}\right.$ ang $\left.=3.10^{\circ} \mathrm{A}\right)$ due to the presence of PPG crystals in the soft segments [19]. Meanwhile, pure COPU presence is demonstrated by one peak at $2 \theta=20.42$ (d ang $=4.345$ ) due to the difference in the chemical structure of the soft segment condition, such as the presence of mono-glyceride and di-glyceride [20]. Moreover, in addition to the diisocyanate in the castor oil based PUs, the reaction to form the urethane linkage between the diisocyanate and hydroxyl groups proceeds. This information is presented in Figure 5 and Table 1.

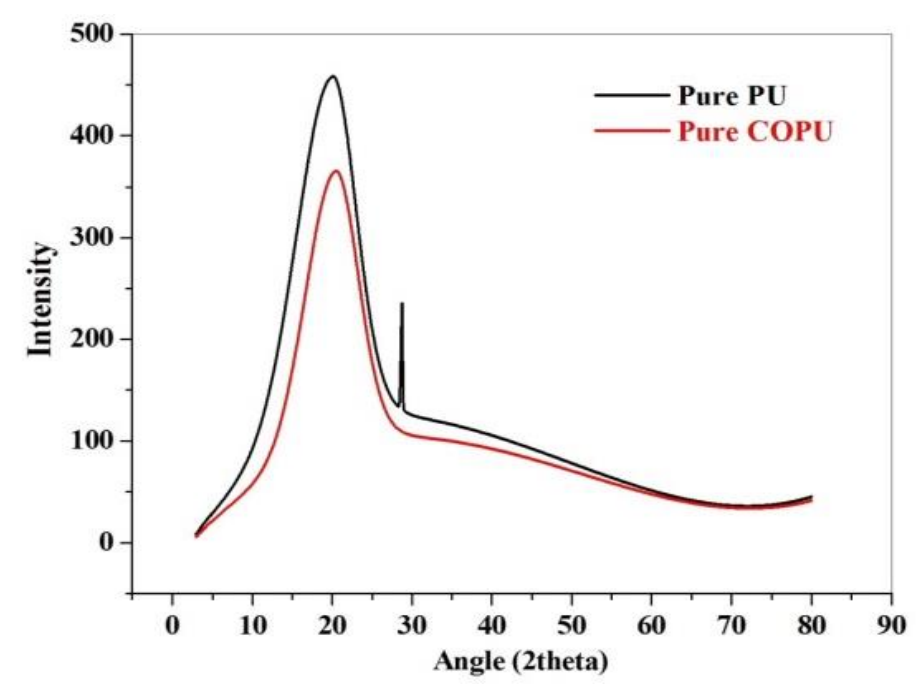

Figure 5. Comparative XRD graphs for the PUs (pure PPG and PPG and castor oil).

Table 1. XRD data for the pure PUs and COPUs

\begin{tabular}{lcc}
\hline Samples & $\mathrm{d} 001[\AA]$ & $2 \theta\left[^{\circ}\right]$ \\
\hline \multirow{2}{*}{ Pure PUs } & 4.52 & 20.03 \\
& 4.35 & 28.77 \\
COPUs & 4.38 & 20.59 \\
\hline
\end{tabular}

\section{SEM}

In pure PU, during the polymerization reaction, isocyanates reacted with the polyol gelation, resulting in the formation of the PU cell wall, as shown in Figure 6a. When castor oil is mixed with PPG as a polyol, the cell wall formation is slower and larger cells form due to the low reactivity of castor oil [3]. The controlled cell formation is exhibited by the addition of castor oil in the PPG glycol, as shown in Figure 6b. Due to the difference in the chemical structure of the soft and hard segments, microphase separation takes place easily, arising from the incompatibility in the PU [21]. Cells that are formed can be controlled with the addition of PPG. The addition of PPG to extend the hard segment is undertaken so that the cell wall is stronger and the formed cell becomes smaller as compared to the COPU cells. 


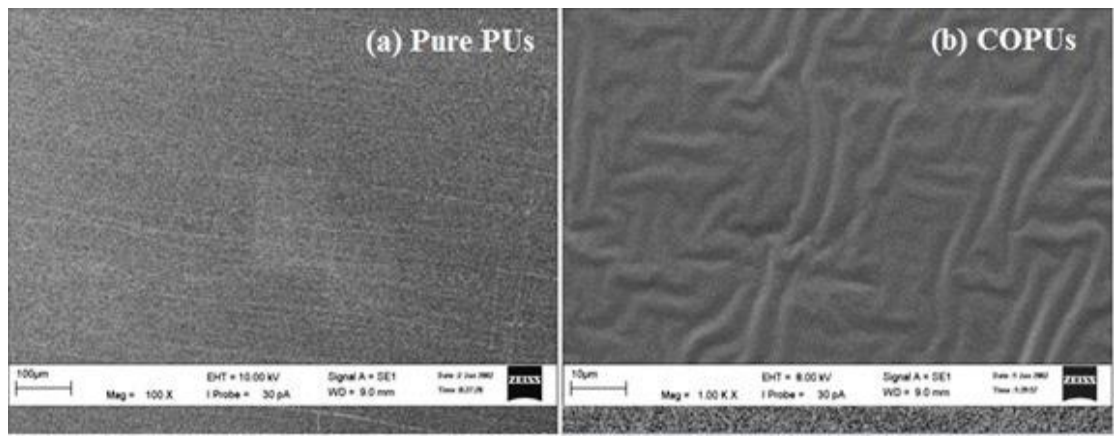

Figure 6. SEM for PUs (a) without, and (b) with castor oil.

\section{Tensile and Mechanical Properties}

Tensile testing was conducted using a tensile universal testing machine. Figures 7 and 8 show the stress-strain and tensile strength curves, respectively, and the effect of castor oil content. An increase in elongation at the break was observed, while the tensile strength was found to decrease in comparison with pure PUs. COPUs showed an improvement of $\sim 21 \%$ in elongation at the break (Figure 7) while its tensile strength decreased to $\sim 35 \%$ (Figure 8 ) when calculated in the comparative stress-strain study of pure PUs and COPUs with $15 \mathrm{wt} \%$ of castor oil. The improved elongation at break of the COPUs may be due to the presence of $\mathrm{CH}-\mathrm{CH}_{3}$ peak stretching that is more prominent in the COPUs then pure PUs. This may be due to the higher double bonds and bigger organic chains present in the COPUs [22]. The results show an increase in the hard segments due to the increase in hydrogen bonding, resulting in more ordered pure PU molecules. The presence of mono-glyceride in castor oil helps control such a reaction due to the low reactivity of the secondary hydroxyl group present in the fatty acid chains [23].

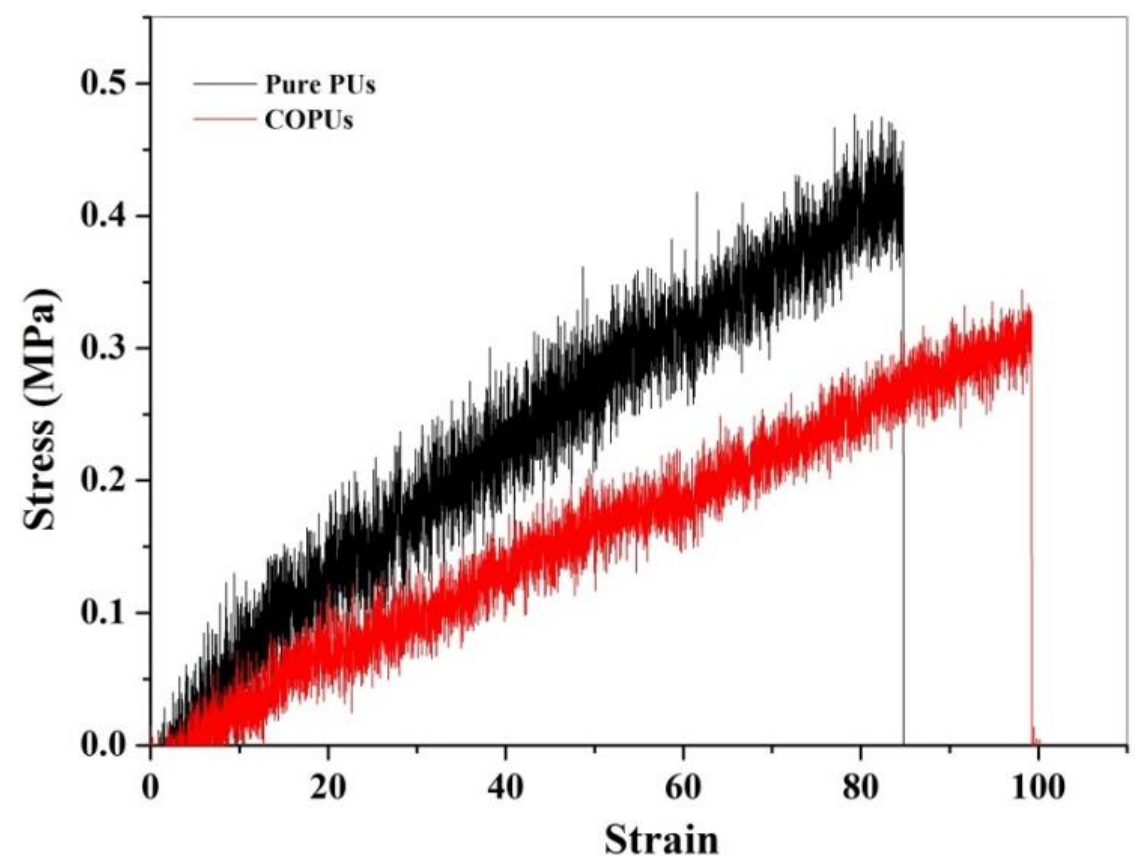

Figure 7. Stress-strain curves for pure COPUs and Pus. 


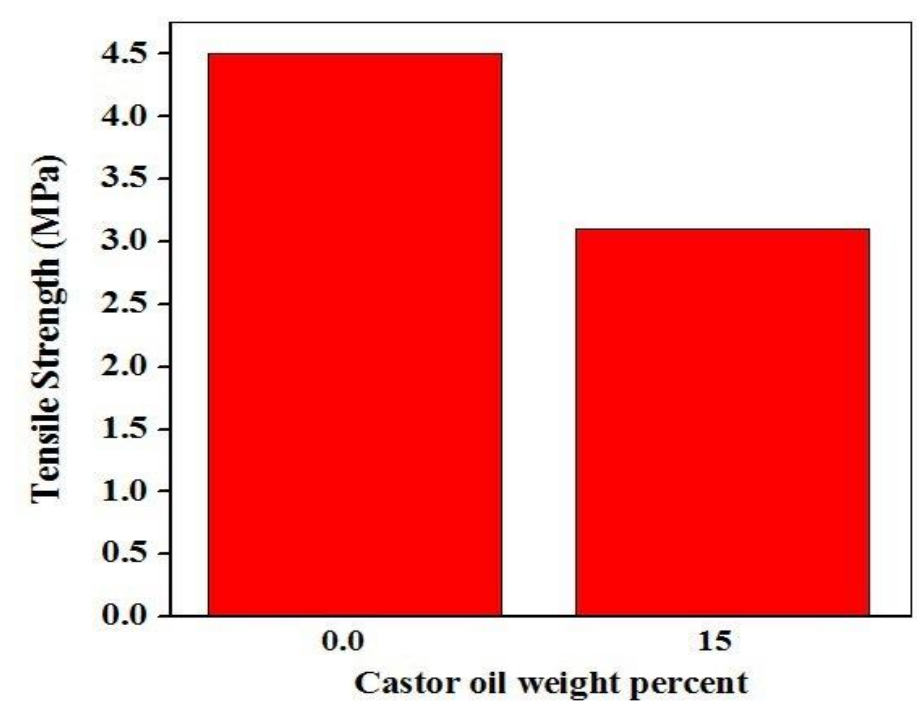

Figure 8. Tensile strength of pure PUs and COPUs with 0 and $15 \mathrm{wt} \%$ of castor oil.

\section{CONCLUSIONS}

The results depicted the enhanced physico-chemical properties of the castor-oil-mixed PUs, over pure PPG originated PUs. The presence of larger organic chains in the castoroil-mixed PUs resulted in a larger oxidative thermal stability over pure PPG PUs. A slower cell formation was also observed in mixed PUs, exhibiting a controlled synthesis. Further studies will be undertaken to enhance the mechanical properties by applying nanofillers. With regard to the mechanical properties, an increase in elongation at break was observed, while the tensile strength was found to decrease in comparison with pure PUs. COPUs showed an improvement of $\sim 21 \%$ in elongation at break while, the tensile strength decreased to $\sim 35 \%$ when calculated in the comparative stress-strain study of pure PU and COPU.

\section{ACKNOWLEDGEMENT}

Authors are thankful to Universiti Malaysia Pahang, for research grant RDU 130329, for the financial support.

\section{REFERENCES}

[1] Lu QW, Macosko CW. Comparing the compatibility of various functionalized polypropylenes with thermoplastic polyurethane (TPU). Polymer. 2004;45:198191.

[2] Cao X, Lee LJ, Widya T, Macosko C. Polyurethane/clay nanocomposites foams: processing, structure and properties. Polymer. 2005;46:775-83.

[3] Edhi P, Adityo WH, Eva ON. Effects of chain extender to the structure of castor oil-based polyurethane foam. International Conference on Chemical and Material Engineering Grand Candi Hotel, Semarang Indonesia; 2012.

[4] Meier MA, Metzger JO, Schubert US. Plant oil renewable resources as green alternatives in polymer science. Chemical Society Reviews. 2007;36:1788-802.

[5] Gaidukov S, Cabulis U, Gromilova K, Tupureina V, Grigalovica A. Preparation and structural properties of free films from rapeseed oil-based rigid 
polyurethane-montmorillonite nanocomposites. International Journal of Polymer Science. 2013; 834595: 1-8.

[6] Pradhan KC, Nayak P. Synthesis and characterization of polyurethane nanocomposite from castor oil-hexamethylene diisocyanate (HMDI). Adv Appl Sci Res. 2012;3:3045-52.

[7] Yang LT, Zhao CS, Dai CL, Fu LY, Lin SQ. Thermal and mechanical properties of polyurethane rigid foam based on epoxidized soybean oil. J Polym Environ. 2012;20:230-6.

[8] Shan CW, Ghazali MI, Idris MI. Improved vibration characteristics of flexible polyurethane foam via composite formation. International Journal of Automotive and Mechanical Engineering. 2013;7:1031-42.

[9] Rojek P, Prociak A. Effect of different rapeseed-oil-based polyols on mechanical properties of flexible polyurethane foams. J Appl Polym Sci. 2012;125:2936-45.

[10] Saravari O, Praditvatanakit S. Preparation and properties of urethane alkyd based on a castor oil/jatropha oil mixture. Progress in Organic Coatings. 2013;76:698-704.

[11] Vashist D, Ahmad M. Statistical Analysis of Diesel Engine Performance for Castor and Jatropha Biodiesel-Blended Fuel. International Journal of Automotive and Mechanical Engineering. 2014;10:2155-69.

[12] dos Santos D, Tavares L, Batalha G. Mechanical and physical properties investigation of polyurethane material obtained from renewable natural source. Journal of Achievements in Materials and Manufacturing Engineering. 2012;54(2): 211-6.

[13] Kaushik A, Ahuja D, Salwani V. Synthesis and characterization of organically modified clay/castor oil based chain extended polyurethane nanocomposites. Composites Part A: Applied Science and Manufacturing. 2011;42:1534-41.

[14] Desantes J, Galindo J, Guardiola C, Dolz V. Air mass flow estimation in turbocharged diesel engines from in-cylinder pressure measurement. Experimental Thermal and Fluid Science. 2010;34:37-47.

[15] Cervantes-Uc JM, Cauich-Rodríguez JV, Vázquez-Torres H, Garfias-Mesías LF, Paul DR. Thermal degradation of commercially available organoclays studied by TGA-FTIR. Thermochimica Acta. 2007;457:92-102.

[16] Cervantes-Uc J, Espinosa JM, Cauich-Rodriguez J, Avila-Ortega A, VazquezTorres H, Marcos-Fernandez A, et al. TGA/FTIR studies of segmented aliphatic polyurethanes and their nanocomposites prepared with commercial montmorillonites. Polymer Degradation and Stability. 2009;94:1666-77.

[17] Coutinho FM, Delpech MC. Degradation profile of films cast from aqueous polyurethane dispersions. Polymer degradation and Stability. 2000;70:49-57.

[18] Javni I, Petrović ZS, Guo A, Fuller R. Thermal stability of polyurethanes based on vegetable oils. J Appl Polym Sci. 2000;77:1723-34.

[19] Sahoo NG, Jung YC, So HH, Cho JW. Synthesis of polyurethane nanocomposites of functionalized carbon nanotubes by in-situ polymerization methods. Journal of the Korean Physical Society. 2007; 51:S1-6.

[20] Zhang L, Zhang M, Hu L, Zhou Y. Synthesis of rigid polyurethane foams with castor oil-based flame retardant polyols. Industrial Crops and Products. 2014;52:380-8.

[21] Gao X, Zhou B, Guo Y, Zhu Y, Chen X, Zheng Y, et al. Synthesis and characterization of well-dispersed polyurethane/CaCO 3 nanocomposites. 
Colloids and Surfaces A: Physicochemical and Engineering Aspects. 2010;371:1-7.

[22] Choi DS, Zhang Z, Pachauri N. Nanoengineered material applications in electronics, biology, and energy harnessing. Microelectronics to Nanoelectronics: Materials, Devices \& Manufacturability. 2012:350-69.

[23] Thakur S, Karak N. Castor oil-based hyperbranched polyurethanes as advanced surface coating materials. Progress in Organic Coatings. 2013;76:157-64. 